\title{
Pituitary-adrenal activity and leverpress shock escape behavior
}

\author{
HANK DAVIS, JOHN W. PORTER, JOAN LIVINGSTONE, THOM HERRMANN, \\ LACHLAN MacFADDEN, and SEYMOUR LEVINE \\ University of Guelph, Guelph, Ontario, Canada \\ and \\ Stanford University School of Medicine, Stanford, California 94305
}

\begin{abstract}
Three experiments were performed to explore the relationship between leverpress escape behavior and pituitary-adrenal activity. In Experiment 1, concentrations of plasma corticosterone increased from basal levels during exposure to the shock escape procedure, but were substantially decreased following the 15th escape conditioning session. In Experiment 2, steroid levels of subjects which received inescapable shock remained elevated during exposure to all 15 shock sessions. Experiment 3 examined whether normal pituitary-adrenal arousal was necessary for learning and maintenance of successful leverpress escape behavior. Subjects for which hypothalamic cortisol implants blocked pituitary-adrenal activity learned the escape response and performed efficiently, although their escape latencies showed a small, but significant, increase over latencies of cholesterol-implanted control subjects. Collectively, these results suggest that pituitary-adrenal activity may reflect rather than mediate the acquisition of coping behavior.
\end{abstract}

It is now widely accepted that elevations in pituitary-adrenal activity result from exposure to conditions generally described as "stressful" (Levine, 1971; Levine, Goldman, \& Coover, 1972). Perhaps the most frequent operational definitions of stress within the psychoendocrine literature involve the traditional array of aversive control procedures (Mason, 1968). Most commonly used among these procedures has been shock avoidance. In a typical experiment, Coover, Ursin, and Levine (1973) monitored the activity of the pituitary-adrenal system during shuttlebox avoidance performance. They reported that as avoidance performance continued to improve over sessions, levels of plasma corticosterone were significantly reduced from values obtained during the initial avoidance session, when pituitary-adrenal functioning had been markedly elevated.

It is not clear whether this reduction in steroids was based upon the subject's increasing "control" over the avoidance procedure or upon the reduction in the number of shocks which resulted from this behavior. Data on the steroid response during escape conditioning would be helpful in elucidating this issue. Although the escape-trained subject may be-

This research was supported in part by Grant AO673 from the National Research Council of Canada (H.D.) and Research Grant NICH\&HD 02881 from the National Institutes of Health (S.L.). Reprints may be obtained from Hank Davis, Department of Psychology, University of Guelph, Guelph, Ontario, Canada. Seymour Levine is supported by USPHS Research Scientist Award K5-MH-19936 from the National Institute of Mental Health. come highly proficient, the escape procedure, unlike avoidance, does not allow the subject to eliminate shock.

It is surprising that no data have yet appeared on pituitary-adrenal functioning during exposure to a leverpress shock escape procedure. Such data are argueably fundamental to understanding the relationship between pituitary-adrenal activity and stress, insofar as the escape procedure represents perhaps the simplest form of aversive control. The subject is capable only of terminating shock; there are typically no warning signals, and no contingency exists for avoiding or postponing delivery of the next shock.

\section{EXPERIMENT 1}

In Experiment 1, the pituitary-adrenal response, assessed through levels of plasma corticosterone, was monitored prior to and during exposure to a sequence of 15 shock escape sessions.

\footnotetext{
Method

Animals

Twelve experimentally naive female Long-Evans rats served as subjects. The animals were approximately 100 days old at the start of training, and all subjects were maintained on free food and water in their home cages throughout the experiment.
}

\footnotetext{
Apparatus

The subjects were tested in Lehigh Valley grid shock chambers with internal dimensions of $12 \times 8 \times 7.5 \mathrm{in}$. $(30.5 \times 20.3 \times$ $19.0 \mathrm{~cm}$ ) (length $\times$ width $\times$ height). The floor consisted of 22 stainless steel grids, $3 / 16$ in. $(0.64 \mathrm{~cm})$ in diameter and spaced
} 
$1 / 2$ in. $(1.3 \mathrm{~cm})$ center to center. A constant current shock generator and shock scrambler (Campden Instrument Co.) was calibrated to deliver a $0.4-\mathrm{mA}$ shock to the grid floor, cage walls, and response lever. The lever was $1 / 2 \times 2$ in. $(1.3 \times 5.1 \mathrm{~cm})$ and protruded $7 / 8$ in. $(2.2 \mathrm{~cm})$ from the front cage wall 2 in. $(5.1 \mathrm{~cm})$ above the grid floor.

\section{Procedure}

Training. Prior to the first experimental session, escape subjects received a single training session in which successive approximations to the leverpress response were reinforced by termination of $0.4-\mathrm{mA}$ shock, programmed to occur every $30 \mathrm{sec}$ from offset to onset. A training criterion of 10 consecutive low-latency ( $2 \mathrm{sec}$ or less) leverpress escape responses was achieved by all subjects within $20 \mathrm{~min}$.

Testing. All subjects were run for 15 daily sessions with 50 shock presentations per session. The intertrial interval (ITI) was fixed at $30 \mathrm{sec}$ and shock intensity remained at $0.4 \mathrm{~mA}$.

Blood sampling. Plasma corticosterone levels were determined in the following manner. At the end of the experimental session, the subject was removed from the test chamber and placed in a jar containing ether. Approximately $0.5 \mathrm{ml}$ of blood was drawn in a heparinized syringe directly from the heart of the anesthetized subject. Blood collection was completed within 1-2 min of the end of the session, a period shown to be rapid enough to prevent a rise in plasma corticosterone resulting from the sampling procedure (Davidson, Jones, \& Levine, 1968). Blood samples were centrifuged to obtain cell-free plasma, which was assayed using the fluorometric method described by Glick, von Redlich, and Levine (1964).

Blood samples were obtained prior to shock exposure, and immediately following the $1 \mathrm{st}, 5 \mathrm{th}, 10 \mathrm{th}$, and 15 th experimental sessions.

\section{Results}

All escape-trained subjects maintained low and stable shock escape latencies. The mean escape latency recorded during Sessions 7-15 was 0.255 sec. During this period, escape subjects spent an average of $84 \%$ of session time "holding" the lever. No significant changes in escape performance appeared across exposure to the 15 experimental sessions. Both escape latency and lever-holding data, as well as the low variability in these measures over sessions, are typical of previously recorded leverpress shock escape performance (cf. Davis \& Burton, 1974).

Levels of plasma corticosterone sampled prior to and during exposure to 15 escape conditioning sessions are illustrated in Figure $1 .^{1}$ Basal values upon which percent increase data are based averaged $16 \mu \mathrm{g} / 100 \mathrm{ml}$. An analysis of variance revealed a significant difference between these values, $F(4,44)$ $=23.84, \mathrm{p}<.001$. Individual comparisons, derived from $t$ tests using the within-subject error term, indicated the following: (a) Basal levels of plasma corticoids were significantly lower than those sampled at any point during escape training (twotailed $\mathrm{p}<.001$ ). (b) The steroid responses following Sessions 1,5 , and 10 were not significantly different. (c) The level of corticoids taken following Session 15, although significantly higher than basal level, was significantly lower than values obtained following Session 1 (two-tailed $\mathrm{p}<.05)$, Session $5(\mathrm{p}<.01)$, and Session $10(\mathrm{p}<.02)$.

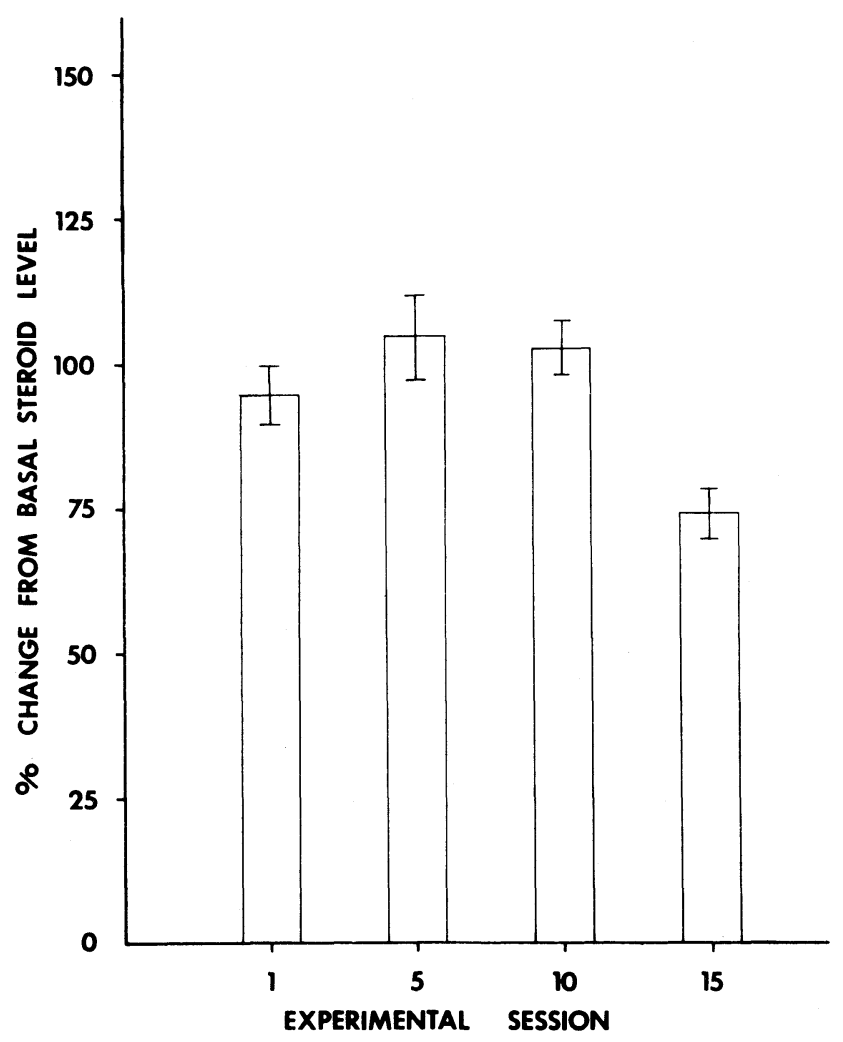

Figure 1. Percent increase from basal in mean levels of plasma corticosterone $(\mu \mathrm{g} / 100 \mathrm{ml})$ obtained from escape-trained subjects prior to testing and immediately following Sessions 1, 5, 10, and 15. Vertical bars represent standard error of the mean.

\section{Discussion}

The pattern of pituitary-adrenal activity recorded during the present leverpress escape procedure is similar to that previously reported for avoidance conditioning (e.g., Coover et al., 1973); i.e., an initial elevation in the steroid response from basal levels is gradually reduced with continuing exposure to the procedure.

It is important to note that, in the present escape situation, this reduction in pituitary-adrenal activity occurred despite the fact that shock continued to be delivered every $30 \mathrm{sec}$ throughout the procedure.

\section{EXPERIMENT 2}

It is not clear from the results of Experiment 1 whether the reduction in pituitary-adrenal activity which occurred over sessions resulted from some form of habituation to shock, per se, or from the the subject's increasing degree of competence or "control" under the escape schedule. In order to distinguish between these two possibilities, the subjects' steroid response was monitored during exposure to 15 sessions of inescapable shock. The number, distribution, and mean duration of shocks in Experiment 2 were identical to those employed in Experiment 1. 


\author{
Method \\ Animals \\ Ten experimentally naive female Long-Evans rats, compar- \\ able in age, weight, and handling to Experiment 1 subjects, were \\ employed.
}

\begin{abstract}
Apparatus
The apparatus was identical to that employed in Experiment 1.

\section{Procedure}

Untrained subjects were run for 15 daily sessions with 50 inescapable shock presentations per session. Shock duration was equal to $0.25 \mathrm{sec}$, the mean latency obtained in Experiment 1 . Shock intensity was set at $0.4 \mathrm{~mA}$, and ITI was fixed at $30 \mathrm{sec}$. The blood sampling procedure was identical to that employed in Experiment 1.
\end{abstract}

\section{Results}

The steroid levels of Experiment 2 subjects are illustrated in Figure 2. ${ }^{1}$ All subjects showed a significant $(p<.01)$ elevation in steroid levels between basal and all subsequent samples. Although basal values were higher than those obtained in Experiment $1(\bar{X}=49 \mu \mathrm{g} / 100 \mathrm{ml})$, the general pattern of steroid elevation was similar. However, unlike escape-trained subjects, there was no decrease in corticosterone levels across 15 sessions of shock exposure.

\section{Discussion}

The subjects in Experiment 2 failed to show any

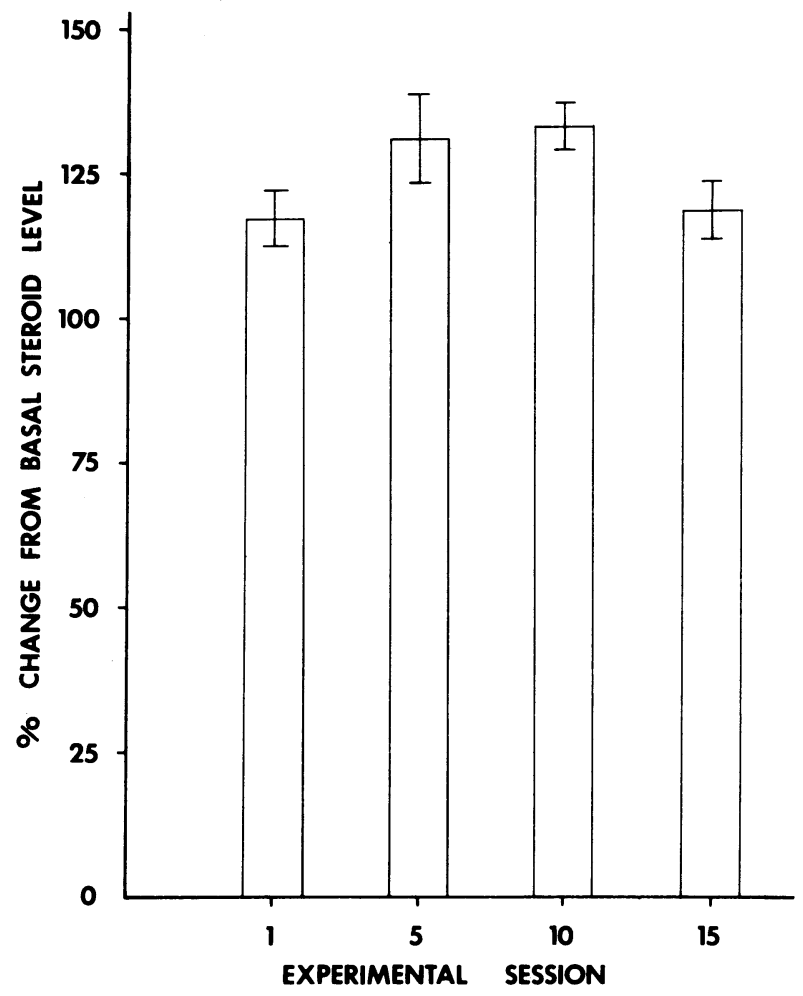

Figure 2. Percent increase from basal in mean levels of plasma corticosterone $(\mu \mathrm{g} / 100 \mathrm{ml})$ obtained prior to testing and immediately following Sessions $1,5,10$, and 15 of exposure to inescapable shock. Vertical bars represent standard error of the mean. significant decrease in corticosterone levels after 15 sessions of inescapable shock. These results represent a missing data point, the importance of which was recently noted by Natelson, Krasnegor, and Holaday (1976). Our findings make it unlikely that the eventual steroid reductions found in either the avoidance or escape situation results from habituation to the physical stressor. Seen in this light, the present data continue to support the notion that psychological factors such as "prediction" (given the regularity of shock delivery) or "control" may be at least as important as the physical events which underlie them in regulating psychoendocrine activity (cf. Seligman \& Meyer, 1970; Weiss, 1971).

\section{EXPERIMENT 3}

Given that successful leverpress escape performance is typically accompanied by an elevated level of corticosterone, the question remains whether the learning and maintenance of such behavior depends upon normal functioning of the pituitaryadrenal axis. Experiment 3 deals directly with this question by examining the escape behavior of subjects for whom normal pituitary-adrenal activity has been blocked by intrahypothalamic implantation of cortisol, a synthetic steroid hormone (Davidson et al., 1968).

\section{Animals}

\section{Method}

Sixteen experimentally naive female Long-Evans rats served as subjects. Animals were approximately 100 days old at the start of the experiment and weighed between 200 and $230 \mathrm{~g}$. The subjects were housed individually with free access to food and water in their home cages.

\section{Apparatus}

The apparatus was the same as that used in Experiments 1 and 2 .

\section{Procedure}

The subjects were divided into an experimental group which received intrahypothalamic implantation of cortisol, known to block pituitary-adrenal activity, and a control group which received an intrahypothalamic implant of cholesterol, an inert substance with regard to pituitary-adrenal activity. Two subjects receiving the cholesterol implant died following surgery.

Implantation. Twenty-gauge cannulae for implantation of $120 \mu \mathrm{g}$ of cortisol or $200 \mu \mathrm{g}$ of cholesterol into the median eminence were constructed and stereotaxically implanted after the method of Erskine and Levine (1973). The criteria used to determine whether or not the implantation of cortisol had produced the expected blockage were (a) plasma corticosterone levels under stress less than $25 \mu \mathrm{g} / 100 \mathrm{ml}$, and (b) visual inspection of the implant site at autopsy to determine whether or not the crystals were properly placed (Davidson \& Feldman, 1963).

Blood sampling. Blood samples and plasma assays were performed as described in Experiment 1. Samples were taken prior to surgery (basal) and immediately following Escape Sessions 3 and 16.

Test procedure. Five days following surgery, the subjects were trained to escape shock as in Experiment 1. The subjects were given 16 daily escape conditioning sessions identical to those in Experiment 1. 


\section{Results}

Figure 3 shows the mean level of plasma corticosterone recorded for subjects receiving intrahypothalamic implantation of cortisol and cholesterol. Basal values upon which percent change data are based averaged $21 \mu \mathrm{g} / 100 \mathrm{ml}$ for cortisol subjects and $15 \mu \mathrm{g}$ for cholesterol subjects. As expected, subjects which received cholesterol treatment exhibited elevated levels of pituitary-adrenal activity under exposure to the shock escape procedure and followed the general pattern reported in Experiment 1 (basal < Day 3, p <.001; Day $3>$ Day 16, $\mathrm{p}<.05)$. The steroid response of subjects implanted with cortisol remained unchanged from basal levels.

A comparison of the escape performance of these two groups of subjects showed a subtle behavioral effect. Although both groups learned to escape shock and continued to perform successfully throughout all sessions, cholesterol subjects, for whom pituitaryadrenal activity was not suppressed, responded with significantly shorter latencies (see Table 1). It should be noted parenthetically that, although the escape latencies of normal subjects in Experiment 1 were longer than those of "normal" cholesterol subjects

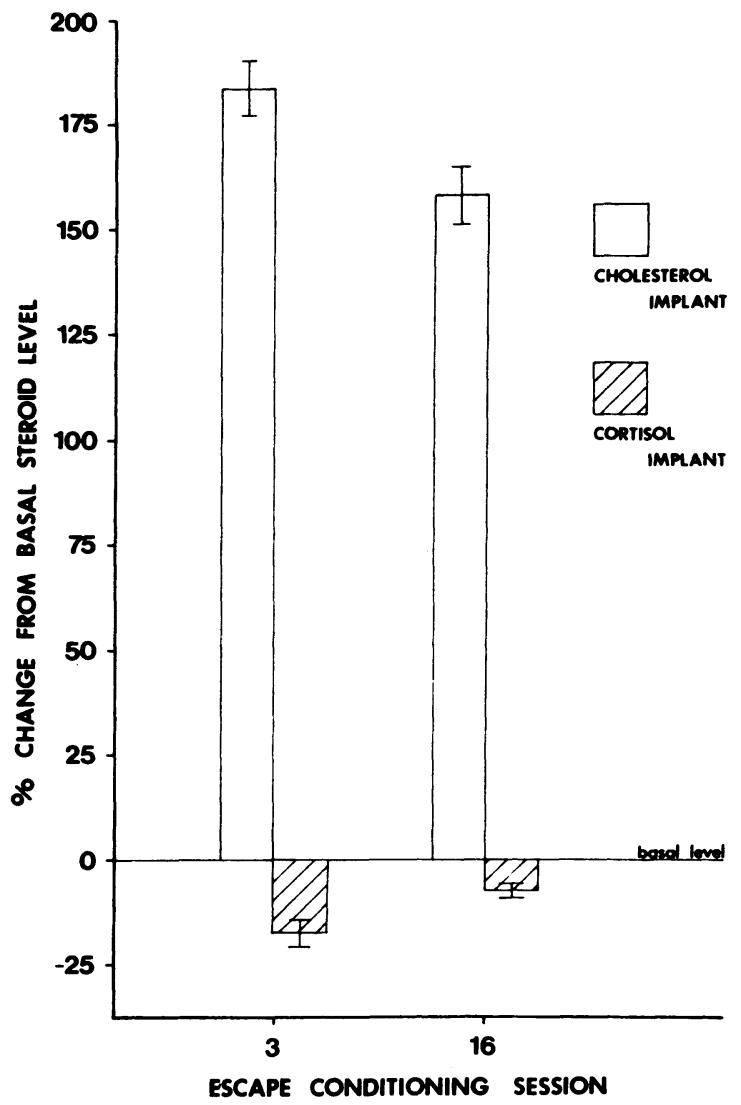

Figure 3. Comparison of mean levels of plasma corticosterone for subjects in which normal pituitary-adrenal activity was blocked by a hypothalamic implant of cortisol, and for control subjects receiving cholesterol implants. Blood samples were obtained prior to surgery and immediately following Escape Sessions 3 and 16. Vertical bars represent standard error of the mean.
Table 1

Mean Escape Latencies (in seconds) for Cortisol and Cholesterol Implanted Subjects Over Final 10 Sessions

\begin{tabular}{ccc}
\hline & Cortisol Implant & Cholesterol Implant \\
\hline & .364 & .199 \\
.278 & .235 \\
.337 & .205 \\
.292 & .169 \\
.314 & .207 \\
& .200 & .196 \\
& .311 & \\
Mean & .314 & .202 \\
\hline
\end{tabular}

Note $-t=4.62, d f=12$, two-tailed $p<.005$

in Experiment 3, these values were still significantly shorter than escape latencies of cortisol-blocked subjects, $t(18)=2.3, p<.05$. Neither the rate at which subjects learned to escape, the topography of the response, nor the amount of lever holding were affected by the cortisol implantation.

\section{Discussion}

Satisfactory escape performance was obtained for all subjects, although animals in which normal pituitary-adrenal functioning was blocked by hypothalamic implants of cortisol showed significantly slower shock escape latencies. The present results thus suggest that, rather than eliminating escape behavior altogether, restricting normal pituitaryadrenal activity results in marginally less efficient performance. This finding is in general agreement with the conclusion of DeWeid, Van Delft, Gispen, Weijnan, and Van Wimersma Greidanus (1972) and Natelson et al., (1976) that normal functioning of the pituitary-adrenal system is not essential for conditioned avoidance behavior, although pituitaryadrenal activity contributes in some way to the avoidance response.

Other than the brief differences in escape latency, cortisol subjects were not observably different from "normal" cholesterol animals. It is somewhat surprising that the total contribution of a normally functioning pituitary-adrenal system to leverpress escape performance would be no more than a 0.10 -sec difference in latency. One might reasonably have expected a more drastic performance decrement to result from blocking a major neuroendocrine coping mechanism (Levine, 1971; Mason, 1968).

Several points should be noted, however. First, although the absolute difference in escape latencies appears small in terms of conventional standards, such a difference may in fact be critical in the natural setting. Put simply, the distinction between "the quick and the dead," especially among members of a species as predator-rich as the rat, may be measured in milliseconds. Second, the nature of the measured response itself must be considered. The 
leverpress escape response depends largely upon reflexive elements and is therefore likely to yield briefer latencies than escape requirements involving grosser motorics, such as alley running (Bolles \& McGillis, 1968; Davis \& Burton, 1974).

The relevance of pituitary-adrenal activity to reflexive behavior has been examined using a procedure similar to the present technique. Johnson (1970) measured a reflexive startle response in subjects for which normal pituitary-adrenal functioning was blocked by chronic hypothalamic implantation of hydrocortisone. Her report that this class of reflexive behavior was suppressed by blocking pituitaryadrenal activity parallels the present findings and suggests that the slight difference in latencies might result from diminution of the reflexive element underlying the leverpress escape response, rather than a deficit in learning an aversively reinforced response (cf. Bohus, 1968; DeWeid et al., 1972; Endröczi, 1972).

\section{GENERAL DISCUSSION}

The relationship between pituitary-adrenal activity and leverpress escape behavior has been explored in three experiments in which levels of plasma corticosterone were used both as an independent and as a dependent variable. The results of Experiments 1 and 2 suggest that although the presence of a physical stressor such as shock is a sufficient condition for initiating pituitary-adrenal activity, the elimination of such a stressor, as occurs in avoidance but not in escape conditioning, is not a necessary condition for obtaining a relative decline in pituitary-adrenal activity. Such a decline was also observed in escapetrained subjects for whom shock continued to occur. Moreover, the failure to observe this decrease in the steroid response of subjects exposed to inescapable shock continues to suggest the importance of psychological factors (e.g., control) in modulating pituitaryadrenal activity (Endröczi, 1972).

The question remains, however, as to what function pituitary-adrenal arousal has in allowing the animal to cope with a stressful situation. Although decreases in pituitary-adrenal activity have been taken to indicate the presence of coping behavior (e.g., Ursin, Coover, Kohler, Derylik, Saguolden, \& Levine, 1975), it is now clear that coping behavior, as presently defined, may occur independently of pituitary-adrenal arousal. Specifically, data from Experiment 3 suggest that an organism may perform efficiently in a shock escape situation despite disruption of normal pituitary-adrenal functioning. Collectively, these results suggest that pituitaryadrenal activity may reflect, more than mediate, the acquisition of coping behavior.

\section{REFERENCES}

Bohus, B. Pituitary ACTH release and avoidance behavior of rats with cortisol implants in mesencephalic reticular formation and median eminence. Neuro-endocrinology, 1968, 3, 355-365.

Bolles, R. C., \& McGillis, D. B. The non-operant nature of the bar-press escape response. Psychonomic Science, 1968. 11. 261-262.

Coover, G., Ursin, H., \& Levine, S. Plasma corticosterone levels during active avoidance learning in rats. Journal of Comparative and Physiological Psychology, 1973, 82, 170-174.

Davidson, J., \& Feldman, S. Cerebral involvement in the inhibition of ACTH secretion by hydrocortisone. Endocrinology, 1963, 72, 936-946.

Davidson, J., Jones, L., \& Levine, S. Feedback regulation of adrenocorticotrophin secretion in "basal" and "stress" conditions: Acute and chronic effects of intrahypothalamic corticoid implantation. Endocrinology, 1968, 82, 655-663.

Davis, H., \& Burton. J. The measurement of response force during a lever-press shock-escape procedure in rats. Journal of the Experimental Analysis of Behavior, 1974, 22, 433-440.

De Weid, D., van Delft, A. M. L., Gispen, W. H., Weijnan, J. A. W. N., \& van Wimersma Greidanus, Tu. B. The role of pituitary adrenal system hormones in active avoidance conditioning. In S. Levine (Ed.), Hormones and behavior. New York: Academic Press, 1972.

ENDRöczI, E. Limbic system learning and pituitary-adrenal function. Budapest: Akadémial Kiado, 1972.

Erskine, M. S., \& Levine, S. Suppression of pituitaryadrenal activity and shock induced fighting in rats. Physiology and Behavior, 1973, 11, 787-790.

Glick, D., von Relich, D., \& Levine, S. Fluorometric determination of corticosterone and cortisol in 0.02-0.05 millilitres of plasma or submilligram samples of adrenal tissue. Endocrinology, 1964, 74, 653-655.

JoHnson, E. T. Influence of pituitary-adrenal hormones on habituation and conditioned avoidance behavior. Unpublished doctoral dissertation, Stanford University, 1970.

Levine, S. Stress and behavior. Scientific American, 1971, 224, 26-31.

Levine, S., Goldman, L., \& Coover, G. Expectancy and the pituitary-adrenal system. In Physiology, emotion and psychosomatic illness. Amsterdam: Ciba Foundation 8, ASP, 1972.

Mason, J. W. A review of psychoendocrine research on the pituitary-adrenal cortical system. Psychosomatic Medicine, 1968, 30, 576-607.

Natelson, B. H., Krasnegor, N., \& Holaday, J. W. Relations between behavioral arousal and plasma cortisol levels in monkeys performing repeated free operant avoidance sessions. Journal of Comparative and Physiological Psychology, 1976. 90, 958-969.

Seligman, M. E. P., \& Meyer, B. Chronic fear and ulceration in rats as a function of unpredictability of safety. Journal of Comparative and Physiological Psychology, 1970, 73, 202-207.

Ursin, H., Coover, G. D., Kohler, C., Derylik, M., SAguolden, T., \& Levine, S. Limbic structures and behaviour. Progress in Brain Research, 1975, 42, 273-284.

WEISS, J. M. Effects of coping behavior in different warning signal conditions on stress pathology in rats. Journal of Comparative and Physiological Psychology, 1971, 77, 1-13.

\section{NOTE}

1. Because of individual variability in basal steroid levels attributable to diurnal cycles, steroid data are reported in terms of percentage change to allow interexperimental comparisons in pituitary-adrenal activity.

(Received for publication November 29, 1976; revision accepted February 22, 1977.) 